\title{
A Metasynthesis Study Related to Exhaustion Concept of Teachers in Turkey
}

\author{
Bekir Barış Cihan ${ }^{1, *}$ \& Ebru Araç Ilgar² \\ ${ }^{1}$ School of Physical Education and Sports, University of Yozgat Bozok, Yozgat, Turkey \\ *Correspondence: School of Physical Education and Sports, University of Yozgat Bozok, Yozgat, Turkey. Tel: \\ 90-505-248-2279. E-mail: bekirbaris|_cihan@hotmail.com
}

Received: August 2, 2018

Accepted: August 23, $2018 \quad$ Online Published: September 27, 2018

doi:10.5430/wje.v8n5p31

URL: https://doi.org/10.5430/wje.v8n5p31

\begin{abstract}
The aim of the research is to determine teachers' exhaustion levels in Turkey, reasons, related factors, different researches the effects of subject areas have been carried out directly about issues in a systematic manner, gathering the studies that have been done over the last decade and making its meta-synthesis. Totally 35 studies consisting of 26 theses and 9 articles determined by the purposeful sampling method between 1998 and 2018 were analyzed by a planned meta-synthesis study in the qualitative research design. In order to determine the studies that will be included in the research; The National Teaching Center of the Higher Education Council, Google Academic search engine, DergiPark, TUBITAK Ulakbim and ERIC databases were used. The sample group of studies used for analysis constitutes exhaustion studies on teachers in public and private schools. According to research findings, the studies carried out mainly concentrated on the four subscales. These are; the studies on the exhaustion and demographic characteristics, the studies on the emotional states and the intelligence dimensions, the studies about the organization and the states of belonging. In conclusion, in the context of the analyses made, it is considered that this study will be useful in terms of future research direction and awareness of the exhaustion that teachers experience.
\end{abstract}

Keywords: Turkey, meta - synthesis, content analysis, teacher, exhaustion

\section{Introduction}

Meta-synthesis (thematic content analysis) include; The studies carried out on the same concept include synthesizing, defining and interpreting the researches with a critical point of view by creating categories, themes or main templates. Meta-synthesis is a study that examines and interprets the findings of multiple researchers (different from raw data). Meta-synthesis studies were interpreted by Noblit and Hare (1988) as the result of cultural studies they were called meta-ethnography. DeWitt-Brinks and Rhodes (1992) then indicated that such studies as a meta-analysis of the nature. Paterson and Canam (2001) named such studies meta-studies. In recent years, these notions have been grouped together under single roof and have been called "meta-synthesis" studies. (Polat and Ay, 2016). Different vocational groups in Turkey related exhaustion was determined that including 825 theses written. When the literature is examined, there is not any meta-synthesis studies observed about exhaustion.

It is seen that there are many definitions made on exhaustion (Peker, 2002). The term of exhaustion was first introduced in 1974 by Freudenberger in an article written by him about health workers' tiredness, depression and job abandonment. Then Maslach examined this concept in detail. When the concept was first put forward, it grabbed much attention and became a subject of various researches. Exhaustion means; emotional exhaustion and numbness in the individual and indicate a psychological problem that arises as a result of a decrease in the sense of personal accomplishment and encapsulate irrelevance (Maslach and Jackson, 1986). It can also be said that high motivation and positive behaviors related to work leave their place to reluctant and aimless behaviors.

\subsection{Types of Exhaustion Model}

When the literature survey was made, these exhaustion model were found, "Cherniss Exhaustion Model," "Edelwich and Brodsky Exhaustion Model," "Pines Exhaustion Model," "Pearlman and Hartman Exhaustion Model," "Meier Exhaustion Model," and "Maslach Exhaustion Model" (Dalkılıç, 2014).

Maslach's exhaustion model: "It is called as three-dimensional exhaustion model. According to Maslach these three 
dimensions are; emotional exhaustion, depersonalization and personal failure feeling "(Maslach, 1998). Maslach has developed a 22-item inventory to measure exhaustion behavior. It is the most commonly used measure in studies.

Suran and Sheridan's exhaustion model: Failure to complete professional development in the individual leads to its role complexity. If the educational needs of the individual are not balanced, the individual's self cannot form a professional integrity. If the individual does the job he likes, he may be more active and expectant in his job. If the individual fails to meet expectations, he may face the danger of exhaustion. When an individual cannot find an environment where he can use his talents, he does not care about his previous successes. Individuals begin to question youth choices in their forties. One might think that he does not actually like the profession he is working on. At this point it leads to exhaustion in the individual (Suran and Sheridan, 1985).

Meier's exhaustion model: While Meier developed this model, he took Bandura's self-sufficiency model as his. Self-sufficiency is the individual's ability to perform behaviors that one can reach. This model has four dimensions (Meier, 1983).

Perlman and Hartman's exhaustion model: According to this model; there is an importance in personal characteristics and social environment in the examination and perception of the effects of exhaustion. The model has four stages (Perlman and Hartman, 1982).

Cherniss exhaustion model: Cary Cherniss is one of the researchers who dealt crucial help in the literature of exhaustion. According to the model developed in 1980, exhaustion is defined as a process that starts as an individual reaction to the sources of stress brought by the worker and ends with a psychological relationship involving stress sources and coping behaviors with work related variances (Yıldırım, 1996).

Pines' exhaustion model: Individuals are described as tired in terms of physical, affective, and mental. The scale developed by Pines and Aronson (1988) is the second most commonly used measure after the Maslach Exhaustion Inventory.

Edelwich's exhaustion model: According to Edelwich, exhaustion has defined workers in jobs in the service sector as a result of business conditions, ideals, energy and the loss of goals. The working conditions causing the exhaustion condition; it is defined as bureaucratic or political pressures, in which a large number of individuals are served, a low salary is paid for it, an excess of working hours, (Sürgevil, 2006).

Education has begun with humanity as an activity. Due to the increase in population, the development and changes in each area, a planned and scheduled training was needed. The need for education that has arisen has anticipated the training of specialists and their work in schools. Therefore, teaching has occurred as a necessity. (Çelikkaya, 1997).

Vocational exhaustion in teachers is seen in people who are idealistic and motivated at the top level. It can be said that the symptoms of exhaustion in the individual started psychologically first. Psychological problems affect the individual physiologically. Physically, there is a feeling of exhaustion and tiredness in the person, frequent headaches, respiratory distress, insomnia, weight loss, memory loss (Gürşimşek ve Girgin, 2000). Exhaustion, unlike depression, is a work-related and more situational problem. It is especially seen in people who start their business with great ideals. It can be said that the professions which started with big dreams have seen an increase together with their frustrations. The sense of exhaustion is not just a teacher; the school, the parents, the family, the classroom management and the environment. Exhaustion is more common in occupations that require face-to-face communication with people. There is a vital relationship between occupation and exhaustion levels of people. Among the problems seen in the teachers in the sector, we are faced with the most professional exhaustion.

In this research on exhaustion in Turkey, it was determined that a large part of the studies carried out to determine the level of exhaustion. In addition, it is seen that the associated variances are also examined. It is thought that the work to be done will enlighten and strengthen the importance of the concept of exhaustion.

\subsection{Purpose and Importance of the Research}

In this study, thesis about the conduct exhaustion in Turkey, articles, and reports of meta-synthesis investigated by using the methods and purposes for which the studies, in which the universe and the sample group, with which method is how attempted to put forward as descriptive as conclusions are reached using which data collection tool. Within the scope of the research, answers to the following questions were searched out.

1 - What are the purposes of exhaustion?

2- Which methods are used and how is the process carried out?

3. Which sample groups are preferred? 
4 - What are the used data collection tools?

5 - What are the acquired results of exhaustion?

\section{Method}

\subsection{Research Pattern}

Research contains the effects of subject areas which are related to the concept of exhaustion research, Turkey's analysis of studies performed over the last decade and their synthesis. Content analyses; with general defining, a group is divided into meta-analysis, meta-synthesis (thematic content analysis) and descriptive content analysis. Compared with meta-analysis and descriptive content analysis, meta-synthesis studies generally have a limited number of studies (Çalık and Sözbilir, 2014). It is also aimed to have a critical view of meta-synthesis studies with a qualitative understanding of the work done in a certain area. Because qualitative method to determine directly made studies regarding exhaustion of teachers in Turkey, meta-syntheses is used. Designing a qualitative design requires an inducible structure from the data collection stage. When social phenomena are examined by qualitative research methods, induction has a central place. The conceptualization of social phenomena is only possible with reasoning (Baltac1 and Balc1, 2017).

\subsection{Limitations of the Research}

Research studies performed between 1998-2018 year covers concepts related to exhaustion in Turkey. The Council of Higher Education has 825 theses on the concept of exhaustion in the National Thesis Center. Exhaustion is a term explored in different vocational groups. Research is limited to 35 theses including 26 theses and 9 articles related to teaching.

\subsection{Collection of Datum}

The studies which were included in the research reached via TÜBİTAK Ulakbim, DergiPark, Google Academic search engine, National Teaching Center of Higher Education Council and ERIC databases. Key words were used when searching the data collection process to determine which studies to include. In the literature review, it has been seen that the "Exhaustion levels", "Exhaustion in teachers", "Exhaustion" keywords related to the topic are used more in studies. The Council of Higher Education has 825 theses on the concept of exhaustion in the National Thesis Center. The concept of exhaustion, which is frequently used in different vocational groups, has been used in educational environments in 124 theses. 83 theses and doctoral theses, which may be appropriate for the purpose of investigating the problem cues individually, were determined. Taking into consideration the inclusion or exclusion criteria of the meta-synthesis studies; Contain the exhaustion concept of the thesis title, to be made in educational settings, must be clearly specified method, master thesis, dissertation and not a scientific article, the sample was limited to criteria such as being within the boundaries of Turkey. Totally 35 studies including 26 master and doctoral theses and 9 articles were prepared using qualitative or quantitative research methods that could serve the purpose.

\subsection{Analysis of Datum, Coding Process, Validity and Reliability Studies}

The relevant parts of each work included in the study are recorded in detail and the obtained data is recorded on the computer. The research was examined according to sub-problems and unnecessary parts were extracted. For articles M1, M2, .., M 9 for each examined study are coded T1, T2, T3 ... T26 for the thesis. The themes summarized in the themes and sub-themes have been coded for each theme. After three weeks of coding, the investigator performed the analysis again. [Reliability $=$ number of overlap $/$ (number of overlap + number of non-overlap)] Expert opinion was taken to increase coherence in the study. With this issue, the validity and reliability of the data was controlled.

\section{Result}

This part encapsulates tables and explanations for the purposes of the studies examined within the scope of the research. The findings concerning the purpose of the work done in the fields of education and exhaustion in Turkey are given in Table-1. 
Table 1. Datum Related to Purpose of Examined Studies

\begin{tabular}{lll}
\hline Purposes & Code & f \\
\hline Examination of Teachers Exhaustion Levels & M4, M6, T7, T11, T12, T15, T21 \\
Exhaustion levels of Principals and Teachers & M2, T3, T13, T18, T22 & 5 \\
Organizational Commitment and Exhaustion levels of Teachers & M3, T1, T9, T16, T26 & 5 \\
Job Satisfaction and Vocational Exhaustion Levels & M1, M5, T10, T14 & 4 \\
Life Satisfaction and Vocational Exhaustion Levels & M7, M9, T2, T19, T23 & 5 \\
Emotional Intelligence and Exhaustion Levels & M8, T4, T8, T24 & 4 \\
Effect of Leadership Styles on Exhaustion Level & T6, T20, T25 & 3 \\
Examination of Organizational Factors that affect Exhaustion & T5, T17 & 2 \\
\hline
\end{tabular}

Most of the examinations when we look at Table 1; consists of examination of the exhaustion levels of the teachers, examination of the exhaustion levels of the managers and the teachers, and the determination of the levels of organizational commitment and exhaustion of the teachers. It is seen that the number of studies performed for other purposes is at the less amount.

Table 2. Methods Used in Exhaustion Studies

\begin{tabular}{|c|c|c|c|}
\hline Method & & Code & $\mathbf{f}$ \\
\hline $\begin{array}{l}\text { Survey, Literature Review, Experiment, } \\
\text { Documents }\end{array}$ & Archive & $\begin{array}{l}\text { M5, T10, T14, M3, T1, T9, T16, T26, T7, } \\
\text { M2, T3, M4, M9, M8, T24, T2, M6, T20, } \\
\text { T4, T5, T17, T8, T11, T12, T15, T21, M1, }\end{array}$ & 27 \\
\hline $\begin{array}{l}\text { Observation, Meeting and Document } \\
\text { Phenomenology, Event Examination, }\end{array}$ & Analysis, & T13, T18, T22, M7, T19, T23, Т6, Т25 & 8 \\
\hline Mixed Method & & & \\
\hline
\end{tabular}

When Table 2 is examined, it is seen that the most quantitative method is used in the researches carried out. Research methods are semi-structured, in-depth interviews with few individuals. It has been determined that no mixed method, including the collection and analysis of quantitative and qualitative data, has been used.

Table 3. Datum Related to Sample Group of Examined Studies

\begin{tabular}{lll}
\hline Sample & Code & $\mathbf{f}$ \\
\hline Teacher & M2, T3, T13, T18, T22, M6, T20, T7, T4, T5, T9, T1 & 62 \\
Principals & M2, T3, T26, M7, T6, T25 & 6 \\
Clasroom Teachers & M4, M9, M8, T24, T2, T17T16 & 7 \\
Branch Teachers & T8, T11, T12, T15, T21, M1 & 6 \\
Highschool Teachers & M5, T10, T14, M3 & 4 \\
\hline
\end{tabular}

As it is seen in Table 3, the sample group that was taken as the teachers in the surveys carried out was the most preferred sample. It is a sample group frequently used only in studies carried out by school Principals. It has been determined that the least preferred group of teachers is high school teachers. 
Table 4. Datum Related to Data Collecting Tools Used in Studies

\begin{tabular}{lll}
\hline Data Collection Tools & Code & f \\
\hline Maslach Exhaustion Inventory & $\mathrm{M} 2, \mathrm{~T} 3, \mathrm{M} 6, \mathrm{~T} 20, \mathrm{~T} 7, \mathrm{~T} 4, \mathrm{~T} 5, \mathrm{M} 5, \mathrm{~T} 24, \mathrm{~T} 17, \mathrm{M} 1, \mathrm{~T} 14, \mathrm{M} 3, \mathrm{~T} 8$, & 2 \\
& $\mathrm{~T} 10, \mathrm{~T} 11, \mathrm{~T} 12, \mathrm{~T} 15, \mathrm{~T} 21, \mathrm{~T} 2$ & 0 \\
Kopenhag Exhaustion Scale & $\mathrm{T} 1, \mathrm{~T} 9, \mathrm{~T} 16, \mathrm{~T} 26, \mathrm{M} 4, \mathrm{M} 9, \mathrm{M} 8$, & 7 \\
Qualitative Studies & $\mathrm{T} 13, \mathrm{~T} 18, \mathrm{~T} 22, \mathrm{M} 7, \mathrm{~T} 19, \mathrm{~T} 23, \mathrm{~T} 6, \mathrm{~T} 25$, & 8 \\
\hline
\end{tabular}

As shown in Table 4, the methods used for the concept of exhaustion were determined in 35 studies that were examined within the scope of the research. The Maslach exhaustion inventory was used in a meaningful part of the work in the national and international literature. It was concluded that the Copenhagen exhaustion scale was used. 8 studies were performed with qualitative research methods without using scale.

Table 5. Datum Related to Acquired Findings in Result of Studies

Result

As the age of the teachers increases, exhaustion levels increase (T15, T21, M4, M9, M8, T4, T10, T11, T16, T14, M3). According to working year variance there are results that have no differentiation exhaustion levels found (T1, T9, T26, T8). In some studies (M2, T3, M6, T20, T24, T17, M1), it was determined that younger teachers experienced more exhaustion.

There was a positive relation between job satisfaction variance and exhaustion. A low exhaustion score was identified when teachers' job satisfaction ratings were high (M5, T14, T10). Job satisfaction consists of the attitudes of teachers towards their jobs. There was no relationship in the study (M1) in order to determine job satisfaction and vocational exhaustion and to reveal the relationship between them.

According to the gender variance, exhaustion scores of male teachers are higher than female ones (M2, T3, M6, T20, T4, T5, M4, M9, M8, M5, T24, T17). Studies have shown that the levels of vocational exhaustion do not differ according to the gender of the teachers (M1, T6, T25, T1, T9, T16, T26 T14). The studies we have investigated have shown that men have more exhaustion than women (T12, T15, T2).

Organizational commitment is the belief, loyalty, dedication that one is bound to. When the studies related to organizational loyalty variances were examined, it was found that the exhaustion level of the teachers with high organizational ties (T16, T26, T9, T1, M3) was low and the teachers with low organizational ties had a high exhaustion level (T17, T5).

It is seen that teachers' exhaustion levels did not differ according to their marital status (M2, T9, M8, T24). Married teachers are more likely to experience exhaustion than single teachers (T8, T11, T12). Unlike this research, there are quite a number of studies in which bachelors experience more exhaustion than married teachers (T4, T15, T21).

According to the results of the research; emotional intelligence on exhaustion was found to be a meaningful predictor (M8, T4). The words emotional intelligence and exhaustion look like two different words of meaning and spelling, but they are related concepts. However, in some studies (T8, T24), it was also found that the exhaustion did not bring a positive or negative effect.

According to the number of children they have, the frequency of studies with high exhaustion levels is multiplied (T14, T21, M9, M8, T3, M6, T11, T12, T26). There are studies (T4, M2, T10) that indicate that the number of children is not an effect on exhaustion (T8, T17, M1, M4, T1) and that the number of children they have has a positive effect on the exhaustion (T4, M2, T10) shows that the number of children is not effective.

According to student number variance in crowded schools there are teachers There are teachers with lesser vocational exhaustion levels (T14, T21, T2, T11, T12, M9, T12, M3) and there are teachers with higher vocational exhaustion levels ( T14, T21, T2, T11).

It has been determined that the life satisfaction variances in the researches (M7, T2, T23, M9, T19) that affect teachers' life satisfaction and exhaustion levels meaningfully affect the exhaustion level in order to determine whether they differ meaningfully according to some variances and to show the relation between them. 
When the vocational exhaustion levels are examined according to the branch variance; (T20, T1, T9, T11, T3, T12, T17, M1, T7, M9, M8) were more exhausted than class teachers. The branch teachers are more likely to have exhaustion (M2, T15, T5, M6, T2, T24) than their class teachers. There are studies (T26, $\mathrm{T} 14, \mathrm{M} 3, \mathrm{~T} 10)$ in which there is no difference between the exhaustion levels of class teachers and branch teachers.

According to socio-economic variance it was determined that teachers with high level of income have experienced less exhaustion (T6, T1, T9, T14, T4, T16, M1, M2, T26, T1, T15, M4, T10, T11). According to economical levels there are studies that have no differentiation in exhaustion levels (M5, T24, M9, T17, T3).

The effects of leadership styles on the exhaustion level have been examined. Transformer leadership dimension was defined as high score (T6) and interactivity leadership dimension (T20). It has been found that officers' perceptions of leadership style variability are highly perceptive and have more transformative leadership perceptions than interactivity leadership styles. It was shown that managers have more transformative leadership behaviors. (T25).

As it is seen in Table 5, the findings related to the concept of exhaustion were investigated in 35 studies and the variances related to direct exhaustion were given. It is seen that the factor that affects the exhaustion level is the job satisfaction factor. In general, it has been determined that demographic characteristics are not very effective when studies of this phenomenon are high.

\section{Discussion}

It is observed that teachers'; vocational exhaustion is more likely to be experienced due to problems such as school-family conflicts, disciplinary problems, crowded classes, inadequacy of physical conditions, the multiplicity of bureaucratic affairs, social criticism, social and political pressures on educational institutions, rewarding and inadequate participation. It was occurred in the study of exhaustion in Turkey. According Boyraz to have high levels of teacher exhaustion (2015) study; they found that there was a meaningful difference depending on the gender variance and that this difference was the exhaustion of male teachers in the level of desensitization. Otacioğlu (2008) found that male teachers experienced more exhaustion than female teachers; Coşkun (2012), on the other hand, found that female teachers experienced more emotional exhaustion than male teachers. From this point of view, it can be seen that various results have been reached according to gender. Korkmaz (2004) stated that female teachers are more desensitized than male teachers. It is predicted that there is no statistical effect on the exhaustion level of the incarnation variance (Izgar, 2000, Kırılmaz, Çoban, 2016, Çelen and Sarp, 2003, Aydın, 2002, Akman, Taşkın , Özden and Çörtü 2010, Dolunay, 2002, Eğriboyun, 2013, Çokluk, 1999). It can be said that teachers do not share the same conditions, do the same work, live positive and negative similarities do not have gender differences.

Akçay, (2016) investigated the relationship between "exhaustion and organizational commitment"; they found that they had moderate emotional exhaustion, low desensitization, and a high level of personal success. As a result of Deniz's study (2014); emotional commitment dimension (identifying with the institution, seeing institutional problems as their own problems, etc.) is higher than other dimensions of attachment. In the Çoban's (2016) survey; that life satisfaction levels do not make a meaningful difference in exhaustion levels, and that they are meaningfully effective at organizational commitment level. Soykan (2012) found that there was a strong negative relationship between organizational commitment and exhaustion, and that as the organizational commitment of the subjects increased, their exhaustion decreased. The analysis revealed that the relationship between teachers' organizational commitment and exhaustion was meaningful. Akgül (2014) found that teachers' emotional exhaustion, the first step of exhaustion, was higher. If there are differences between values of employees, values of employees, or if the organization does not depend on its designated goals, inconsistencies arise and it can be said that this inconsistency causes individuals to experience exhaustion. When studies in Turkey are examined, together with individuals and organizations being aware of the negative impact that energy, power, or the depletion of resources through excessive demands, a progressive process of stress, loss of idealism. burnout that can be stated in forms has become a crucial field of study.

Different results were found for the effect of age variance on teachers' vocational exhaustion. The Job exhaustion of teachers showed a meaningful difference in the dimension of emotional exhaustion and personal achievement according to the age variance but showed a meaningful difference in the dimension of desensitization (Izgar, 2000, Kırılmaz, Çoban, 2016, Çelen and Sarp, 2003, Aydın, 2002, Akman, Taşkın, Özden and Çörtü 2010, Dolunay, 2002, 
Eğriboyun, 2013, Çokluk, 1999). And Dolunay (2002) found that the teachers' age relationship was inversely related. According to the study of fullness, as age increases, emotional exhaustion and depersonalization decrease, whereas personal sense of accomplishment increases. Dworkin (2001) notes that one's exhaustion is seen more in the beginning of teaching. Boyraz (2015) in his work titled "The Relationship between Conflict Management Strategies and Exhaustion Levels of Teachers"; the age variance shows a meaningful difference and this difference is that the young teachers' personal achievement levels are higher than the other group. They found that there was no meaningful relationship between age and exhaustion (Izgar, 2000, Kırılmaz et al., 2003). Metin and Saçan (2017) found that the age variance did not show a meaningful difference in the dimensions of emotional exhaustion and depersonalization of the teachers, and they showed a meaningful difference in personal achievement dimension. Taşğın (2004) and Yerlikaya (2000) have emphasized that their studies have an effect on the level of vocational exhaustion of seniority and duration of service. Ağaoğlu et al. (2004) emphasized that elderly teachers experienced vocational exhaustion according to their work experience. It can be assumed that the reason for this discrepancy between views is due to the difference in the criteria by which the parties base their evaluation. Job exhaustion in general newly beginner teachers are experienced in Turkey. For this reason, what the experienced teachers learn to deal with problems can be explained as the disappointment of young teachers.

Varied results have been achieved according to the type of institution employed in the professional exhaustion levels of teachers. Metin and Saçan (2017) found that the teachers they studied did not show a meaningful difference in the exhaustion of the institutional group. Yalçın (2011) study of the relationship between exhaustion levels and empathic tendencies of teachers working in private educational institutions showed that as the empathic tendency of the trainers decreased, the levels of emotional exhaustion, depersonalization and personal achievement scores increased and therefore exhaustion increased. Akınc1 (2016) stated that in the study titled "Exhaustion Levels of Teachers in Private Education Institutions and Public Schools"; found that teachers working in public schools had a higher exhaustion dimension than teachers working in private schools. It has been found that teachers who work in private schools experience less emotional exhaustion and desensitization than teachers who work in public schools and experience more personal success (Korkmaz, 2004). Eğriboyun (2013) according to school type; it was found that exhaustion levels of teachers working in state school Karacan (2012) are over the averages in all sub-dimensions, indicating that there is a meaningful relationship between perceptions of organizational commitment and normative commitment. It can be said that the motivations of the teachers working in the private school are at a high level because of the loss of work.

Metin and Saçan (2017) determined that the number of children in the classroom of teachers pointed out a meaningful difference in the degree of emotional exhaustion of their exhaustion. It can be said that the crowded classes have increased the professional exhaustion of the teachers. Izgar (2000) "School Principals' Exhaustion Levels, Causes According to Some Factors " revealed that there was an inverse relationship between the number of students in the school and the exhaustion. Looking at the duration of the work it seems that the problems are still alive and have not been updated. Torun (1995) "In the exhaustion study, it has been found that the material situation variance has little effect on exhaustion. Aydın (2002) in the study of "Determination of Individual Exhaustion Levels of Primary School Principals"; the economic situation and the seniority of the manager are on the individual failure and exhaustion. With the light of these findings social, economic and social prosperity are affected by the psychological well-being of the individual. Izgar (2000) found a meaningful relationship between the branch of the teachers and emotional exhaustion. In the study, Egriboyun (2013) found that there was no meaningful difference in perceptions of organizational commitment, emotional commitment, continuity and normative commitment in the study. (Tuğrul, B and Çelik, E. 2002; Gündüz, 2004). Face to face method with elementary school students who are dependent on teachers, it is thought that working for a long time increases the exhaustion.

Job satisfaction occurs from the attitudes that employees have developed against their jobs. In Peker's (2002) study, there is a negative relationship between the level of job satisfaction from the teaching profession and exhaustion. As the spiritual satisfaction of the teachers increases, the levels of exhaustion decrease. In Akçamete, Kaner and Sucuoğlu's (1996) researches, it is revealed that there is a relationship between exhaustion and job satisfaction in the high and reverse direction, and as the job satisfaction increases, the exhaustion decreases. It can be argued that working environments in which people spend most of their lives are a dominant influence on the individual's job satisfaction and quality of life. Job satisfaction is the satisfaction or dissatisfaction of one's work. Satisfaction emanates only when the characteristics of the job match the individual's desires. While the level of job satisfaction in Turkey increases there is a reduction seen in emotional exhaustion levels. In other words, it can be said that teachers who have less emotional exhaustion have job satisfaction and experience less exhaustion. 


\section{Conclusion}

Teachers generally experience exhaustion in their works and this is derived from many reasons mentioned above. Even people who work in different types of fields may be exposed to this situation because a person, who is not satisfied what he/she does, or when there is no spiritual income in what they do for their jobs they probably keep themselves out from real life happiness. Everything is in a chain in our life and all of us should be aware of the difficulties in our jobs.

As a result of the research, it was observed that the tendency of exhaustion was increased especially in life satisfaction, organizational commitment, ages and branch variances. Psychological disturbances such as stress, organizational weakness, absenteeism, physiological disorders in individual terms, behavioral disorders and anxiety, depression, "exhaustion" can lead to stress that can affect workers at all levels. Therefore, it is suggested that more emphasis should be placed on personal and social services to reduce or prevent these individual factors on the teachers. This issue is reflected in the institutional politics that are followed in the schools through numerous activities. It is indicated that qualitative researches should be carried out as well, since the studies performed out are widely quantitative and general survey studies.

\section{References}

Adıgüzel, İ. (2016). The relationship between classroom management skills and exhaustion levels of preschool teachers. Master Thesis. Recep Tayyip Erdoğan University, Rize.

Ağaoğlu, E., Ceylan, M., November, E., \& Madden, T. (2004). Opinions of Research Assistants Regarding Their Exhaustion Levels. XIII. National Educational Sciences Congress. Malatya.

Akçay, Y. Y. (2016). Relationship Between Exhaustion and Organizational Commitment: A Research on Health Care Services Employees in a Private Hospital in Istanbul. Master Thesis, Istanbul Arel University, Istanbul.

Akgul, Z. (2014). An Examination of the Relationship Between Organizational Commitment and Exhaustion According to Perceptions of Mathematics Teachers. M.Sc. Thesis, Cumhuriyet University, Sivas.

Akınc1, M. (2016). Exhaustion Levels of Teachers in Special Education Institutions and Public Schools. Graduate Thesis, Beykent University, Istanbul.

Akman, B., Taşkın, N., Özden, Z., \& Çörtü, F. (2010). A study on preschool teachers' exhaustion. Elementary Education Online, 9(2), 807-815.

Aydın, L. (2002). Determination of Individual Exhaustion Levels of Primary School School Principals. Master Thesis, Sakarya University, Sakarya.

Baltaci, A., \& Balc1, A. (2017). Complexity Leadership: A Theorical Perspective. International Journal of Educational Leadership and Management, 5(1), 30-58. http://dx.doi.org/10.17583/ijelm.2017.2435

Boyraz, S. (2015). The Relationship Between Teachers' Conflict Management Strategies and Exhaustion Levels. Master Thesis, Sabahattin Zaim University, Istanbul

Coşkun, M.K. (2012). Examination of exhaustion levels of religious culture and moral teachers according to various variances. Electronic Journal of Social Sciences, 11(41), 64-77.

Çalık, M., Sözbilir, M. (2014). The parameters of the content analysis. Education and Science, 39 (174), 33-38.

Çelikkaya, H. (1997). Introduction to training. İstanbul: Alfa Printing Publishing Delivery.

Çoban(2016) Examination of the Relationships between Life Satisfaction Levels of Exhaustion and Organizational Commitment Levels in Corporate Company Employees M.Sc. Thesis, Beykent University Istanbul.

Çokluk, Ö. (1999). Examination of exhaustion in managers and teachers who work in the mental and hearing impaired school. Ankara University, Ankara.

Dalkılıç, O. S. (2014). Job Life Exhaustion Syndrome Exhaustion Techniques. Ankara: Nobel Publications.

Deniz, A. (2014). Examination of Organizational Commitment of Teachers in Primary Education Institutions in the City Center and Villages with Various Variances. Graduate Thesis, Balıkesir University, Balıkesir.

DeWitt-Brinks, D., \& Rhodes, S. C. (1992). Listening instruction: A qualitative meta-analysis of twenty-four selected studies (Rep. No. Clearinghouse: CS507954). US: Michigan. ED351721

Dolunay, A. (2002). Examination of exhaustion status in teachers working in general high school and technical-trade 
vocational high schools in Kecioren county. Ankara University. Medical Faculty Journal, 1, 51-62.

Dolunay, A. B. (2002). "Exhaustion Situation in Teachers in General High School and Technical-Commerce-Vocational High School". Ankara University, Medical Faculty Journal, 55(1).

Dworkin, A. (2001). Perspectives on teacher exhaustion and school reform. International Education journal, 4(2).

Eğriboyun, D. (2013). The Relationship between Organizational Trust, Organizational Support and Organizational Commitment of Principals and Teachers in Secondary Schools. Abant Izet Baysal University, Doctoral Thesis. Bolu.

Gündüz, B. (2004). Predictors of Exhaustion in Teachers According to Unreasonable Beliefs and Some Professional Variances. Obtained from Internet on December 20, 2004: Çukurova University Institute of Social Sciences, Social Sciences Institute Theses. Adana.

Gürsimsek, I., \& Girgin, G. (2000). The exhaustion level observed in the teachers who serve in the schools attached to the Ministry of National Education in the sample of İzmir.

National Teacher Training Symposium (10-12 May) (p.315). On Sekiz Mart University, Faculty of Education. Çanakkale.

Izgar, H. (2000). Exhaustion of School Principals (Exhaustion), Reasons and Examination according to Some Factors, Ph.D Thesis, Selcuk University, Konya.

Izgar, H. (2001). School Principals Exhaustion Levels. Journal of Theory and Practice in Education Management, Issue: 27 (335-340). 24

Karacan, A. (2012). Examination of vocational exhaustion of teachers working in trainable and teachable individuals in special education institutions "Istanbul province of Anatolia coastal sample". Master Thesis. Maltepe University, Istanbul.

Kırılmaz, A.Y., Çelen, Ü., \& Sarp, N. (2003). A study of exhaustion in a group of teachers working in primary education, Primary school Online, 2(1), 2-9.

Korkmaz, Ö. (2004). Vocational Exhaustion Levels of Music Teachers. Marmara University, Atatürk Education Faculty. Journal of Educational Sciences, 20, 125-148.

Maslach, C. (1998). Prevention of Exhaustion: New Perspectives, Applied and Preventive Psychology.

Maslach, C., \& Jackson, S.E. (1986). Maslach Exhaustion Inventory Manual, Consulting Psychologists Press (2.vol.). Palo Alto, CA: Consulting Psychology.

Meier, S. T. (1983). Towards A Theory of Exhaustion. Human Relations, 36(10), 899-910. https://doi.org/10.1177/001872678303601003

Metin, Ş., \& Saçan, S. (2017). An analysis of the effects of pre-school teachers' exhaustion levels on job satisfaction. International Journal of Family, Child and Education, 11, 44-67.

Miles, M, B., \& Huberman, A. M. (1994). Qualified data analysis: An expanded Sourcebook (2 ${ }^{\text {nd }}$ ed.). Thousand Oaks, CA: Sage.

Noblit, G. W., \& Hare, R. D. (1988). Meta-ethnography: Synthesizing qualitative studies (Vol. 11) Newbury Park: Sage. https://doi.org/10.4135/9781412985000

Otacioğlu, S. G. (2008). Exhaustion syndrome and effecting factors in music teachers. İnönü University, Journal of Education Faculty, 9(15), 103-116.

Öztürk, A., \& Deniz, M. E. (2008). Analysis of emotional intelligence job satisfaction and exhaustion levels according to preschool teachers. Elementary Online, 7(3), 578-599.

Paterson, B. L., \& Canam, C. (2001). Meta-study of qualitative health research: A practical guide to meta-analysis and meta-synthesis (Vol. 3). Sage. https://doi.org/10.4135/9781412985017

Peker, R. (2002). Some Factors Affecting Vocational Exhaustion of Teachers in Primary Schools. Journal of Uludă University Faculty of Education, X(1), 305-318.

Perlman, B., \& Hartman, E. (1982). Exhaustion: Summary and Future Research. Human Relation, 35, 283-305. https://doi.org/10.1177/001872678203500402

Pines, A., \& Aronson, E. (1988). Career Exhaustion; Causes \& Cures. The Free Pres. New York: a Division of 
Macmillan, Inc.

Polat, S., \& Ay, O. (2016). Meta-synthesis: a conceptual analysis. Journal of Qualitative Research in Education, 4(2), 52-64. https://doi.org/10.14689/issn.2148-2624.1.4c2s3m

Soykan, E. (2012). The Relationship Between Organizational Commitment and Exhaustion: An Application in Education Sector. Master Thesis, Dicle University, Diyarbakır.

Sucuoğlu, B., \& Kuloğlu-Aksaz, N. (1996). Evaluation of Exhaustion in Teachers Working with Disabled Children. Turkish Journal of Psychology, 10(36), 44-60.

Suran, B. G., \& Sheridan, E. P. (1985). Management Of Exhaustion: Training Psychologists In Professional Life Span Perspectives. Professional Psychology: Research And Practice, 15(6), 741-752. https://doi.org/10.1037/0735-7028.16.6.741

Sürgevil, O. (2006). Working Life Exhaustion Syndrome and Exhaustion Dealing Techniques. Ankara: Nobel Publication Distribution.

Taşğın, Ö. (2004). "The Impact of the Exhaustion Levels of General Directorate of Youth and Sports, Central and Provincial Organizations on Job Satisfaction Levels". Unpublished Doctoral Thesis, Selçuk University Social Sciences Institute, Konya

Torun, A. (1995). A Review on Relationships between Exhaustion, Family Structure and Social Support. Doctoral Thesis, Marmara University, Istanbul.

Tuğrul, B., \& Çelik, E. (2002). Exhaustion in Kindergarten Teachers Working with Normal Children. Pamukkale University. Journal of Education Faculty, 2(12).

Yalçın, M. (2011). The relationship between exhaustion levels of empathic tendencies and some variances of educators working in special education institutions. Gaziantep University, Institute of Social Sciences, Master Thesis, Gaziantep.

Yerlikaya, A. (2000). "Examination of Exhaustion Levels in Classroom Teachers in Villages and Towns", Unpublished Master Thesis, Atatürk University Social Sciences Institute. Erzurum.

Y1ldırım, F. (1996). Job satisfaction in bank employees and the relationship between perceived role conflict and exhaustion. Unpublished master thesis, Hacettepe University Social Sciences Institute. 